Dorowin

Retter des Abendlands 
HERMANN DOROWIN

\title{
Retter des Abendlands
}

\author{
Kulturkritik im Vorfeld \\ des europäischen Faschismus
}


CIP-Titelaufnahme der Deutschen Bibliothek

Dorowin, Hermann:

Retter des Abendlands : Kulturkritik im Vorfeld des europäischen Faschismus / Hermann Dorowin. - Stuttgart :

Metzler, 1991

(Metzler Studienausgabe)

ISBN 978-3-476-00747-6

ISBN 978-3-476-00747-6

ISBN 978-3-476-03351-2 (eBook)

DOI 10.1007/978-3-476-03351-2

Dieses Werk einschließlich aller seiner Teile ist urheberrechtlich geschützt. Jede Verwertung außerhalb der engen Grenzen des Urheberrechtsgesetzes ist ohne Zustimmung des Verlages unzulässig und strafbar. Das gilt insbesondere für Vervielfältigungen, Übersetzungen, Mikroverfilmungen und die Einspeicherung und Verarbeitung in elektronischen Systemen.

(C) 1991 Springer-Verlag GmbH Deutschland

Ursprünglich erschienen bei J. B. Metzlersche Verlagsbuchhandlung

und Carl Ernst Poeschel Verlag GmbH in Stuttgart 1991 
Diese Arbeit ist unter dem Titel ,Kulturkritik im Vorfeld des europäischen Faschismus. Henri Massis, Ramiro de Maeztu, Leopold von Andrian als komparatistische Dissertation von der Universität Bonn angenommen worden. Der viel zu frühe Tod von Herrn Prof. Erwin Koppen nimmt mir die Möglichkeit, ihm für die geduldige Betreuung und für all das mir bewiesene Vertrauen zu danken. Besonderen Dank schulde ich auch Herrn Prof. Rafael Gutiérrez-Girardot, in dessen Seminar über den Spanischen Bürgerkrieg ich die erste Anregung zu dieser Arbeit erhielt und der mir durch zahlreiche Hinweise hilfreich war. Herr Prof. Wendelin Schmidt-Dengler hat mir freundlicherweise den Briefwechsel seines Onkels Filip Schmidt-Dengler mit Leopold von Andrian zur Einsichtnahme überlassen. Das aufmunternde Interesse meiner Freunde, allen voran Hartmut Kiltz und Ulrich Weinzierl hat mir entscheidend weitergeholfen. Christoph Helferich und Paul Rentrop haben sich als kritische Leser bewährt. Meinen Eltern danke ich für jahrelange vertrauensvolle `Forschungsförderung', Roberta, Amaranta und Tommaso für das liebevolle Verständnis, das sie mir entgegengebracht haben. Die Arbeit ist der Erinnerung an Franz Fritsch (1954-1986) gewidmet. 
Vorbemerkung $\ldots \ldots \ldots \ldots \ldots \ldots \ldots \ldots \ldots \ldots \ldots \ldots \ldots \ldots \ldots \ldots$

Teil I: Henri Massis: `Défense de l'Occident‘

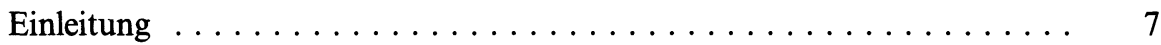

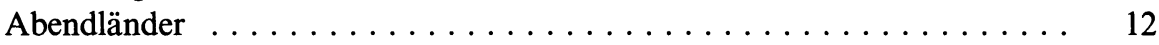

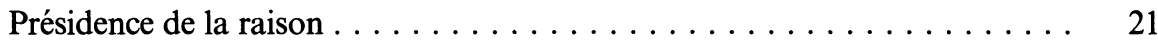

Der Widerspenstigen Zähmung $\ldots \ldots \ldots \ldots \ldots \ldots \ldots \ldots \ldots$

Teil II: Ramiro de Maeztu: >Defensa de la Hispanidadk

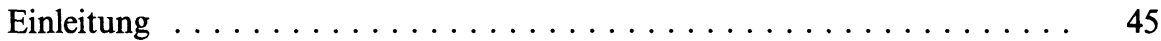

Über den (bedingten) Vorrang des Geistigen $\ldots \ldots \ldots \ldots \ldots \ldots \ldots \quad 50$

Die alten Zünfte und der neue Staat $\ldots \ldots \ldots \ldots \ldots \ldots \ldots \ldots \ldots \ldots \ldots \ldots$

Der Aufstand der Massen $\ldots \ldots \ldots \ldots \ldots \ldots \ldots \ldots \ldots \ldots \ldots$

Teil III: Leopold von Andrian: `Österreich im Prisma der Idee`

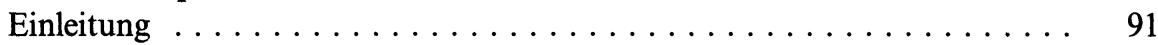

Kosmische und andere Hierarchien $\ldots \ldots \ldots \ldots \ldots \ldots \ldots \ldots \ldots . \ldots 9$

Dein Reich komme . . . . . . . . . . . . . . . . . . . . . 111

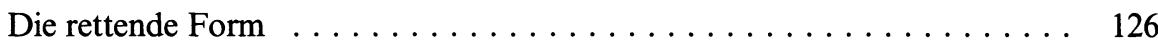

Schluß . . . . . . . . . . . . . . . . . . . . 141

Anmerkungen . . . . . . . . . . . . . . . . . . . . 147

Literaturverzeichnis . . . . . . . . . . . . . . . . . . . . . . 197

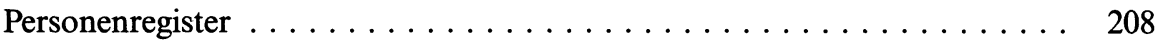

